\title{
COMMENTARY
}

\section{Human umbilical cord mesenchymal stromal cells in regenerative medicine}

\author{
Michael S Detamore
}

See related research by Chon et al., http://stemcellres.com/content/4/5/120

\begin{abstract}
Cells of the human umbilical cord offer tremendous potential for improving human health. Cells from the Wharton's jelly (umbilical cord stroma) in particular, referred to as human umbilical cord mesenchymal stromal cells (HUCMSCs), hold several advantages that make them appealing for translational research. In the previous issue of Stem Cell Research \& Therapy, Chon and colleagues made an important contribution to the HUCMSC literature not only by presenting HUCMSCs as an emerging cell source for intervertebral disc regeneration in general and the nucleus pulposus in particular, but also by demonstrating that an extracellular matrix-based strategy might be preferred over the use of growth factors. By culturing HUCMSCs under hypoxia in serum-free conditions in the presence of Matrigel with laminin-111, they were able to achieve intense collagen II staining by 21 days without the addition of exogenous growth factors. There is tremendous translational significance here in that such raw materials may alleviate the need for the use of growth factors in some instances, and this may have important ramifications in reducing product cost and streamlining regulatory approval. Chon and colleagues provide a promising example of the potential of HUCMSCS, demonstrating the ability to guide HUCMSC differentiation even in the absence of serum and growth factors and supporting the use of HUCMSCs as a viable alternative in intervertebral disc regeneration.
\end{abstract}

Correspondence: detamore@ku.edu

Department of Chemical and Petroleum Engineering, University of Kansas, 4132 Learned Hall, 1530 W 15th Street, Lawrence, KS 66045, USA
Cells from the human umbilical cord offer tremendous potential for improving human health. Although the umbilical cord blood and even the endothelial cells from the umbilical cord vein have captured most of our attention, the bulk of the umbilical cord - that is, the stroma (also known as Wharton's jelly) - is a mesenchymal cell source with tremendous potential. These cells have been referred to as human umbilical cord mesenchymal stromal cells (HUCMSCs), Wharton's jelly cells, and human umbilical cord stroma-derived mesenchymal stem cells. In the previous issue of Stem Cell Research \& Therapy, Chon and colleagues [1] made an important contribution to the HUCMSC literature not only by presenting HUCMSCs as an emerging cell source for intervertebral disc (IVD) regeneration in general and the nucleus pulposus in particular, but also by demonstrating that an extracellular matrix-based strategy might potentially surpass a growth factor-based strategy.

HUCMSCs have been generating a tremendous level of interest, especially in the last 10 years [2]. Following pioneering studies on the differentiation potential of HUCMSCs, these cells were introduced to the threedimensional musculoskeletal tissue engineering literature in 2007 [3]. Since then, their use has exploded in musculoskeletal tissue engineering [4] as an alternative to other popular mesenchymal cell sources such as bone marrow and adipose tissue. Within the musculoskeletal realm, investigators have only recently turned their attention with HUCMSCs to the IVD [5,6].

In their study of HUCMSCs for the IVD, Chon and colleagues pooled HUCMSCs from three donors and seeded them on top of Transwell inserts pre-coated with laminin111-containing Matrigel. The 'pseudo-three-dimensional' aspect of their study came from the incorporation of a 2.5\% Matrigel solution rich in laminin-111 into serumfree medium. This medium composition represented their control group, which was compared with groups that contained either transforming growth factor (TGF)- $\beta 1$ or 
insulin-like growth factor-I. It is noteworthy that all groups were cultured under hypoxia $\left(2 \% \mathrm{O}_{2}\right)$, as others have previously shown that hypoxia clearly influences HUCMSCs [7], an important point for others considering the use of HUCMSCs in regenerative medicine.

The most exciting result, in my opinion, was that Chon and colleagues were able to achieve intense collagen II staining in their control group, as can be seen in Figure four of their article. Generally, they observed no clear improvement in nucleus pulposus-like phenotype for HUCMSCs with the addition of growth factors to their laminin-111-containing Matrigel system. Although it would be interesting to tease out whether it was the hypoxia or the laminin-111 (or their combination with each other or some other factor or both) that led to this result, it was very encouraging to see the emergence of collagen II staining over the 21-day period of the study, given the challenges with collagen II expression that have been observed in the past [8]. The collagen II staining in the control group was arguably more intense than even the group containing TGF- $\beta 1$, although it should be noted that the TGF- $\beta 1$ group led to higher aggrecan gene expression than the control. More specific to the nucleus pulposus, it was also encouraging to see that the HUCMSCs expressed extracellular matrix proteins of laminin $\alpha 5$ as well as laminin receptors (integrin $\alpha 3$ and $\beta 4$ subunits).

Favorable collagen II staining in the absence of growth factors as observed by Chon and colleagues may lend credibility to the emerging philosophy that extracellular matrix molecules, in addition to being valuable building blocks or 'raw materials' in regenerative medicine, might prove to be valuable signaling molecules [9]. There is tremendous translational significance here, in that such raw materials might alleviate the need for the use of growth factors in some instances, and this may have important ramifications in reducing product cost and streamlining regulatory approval.

As our field moves forward with HUCMSCs in IVD and other musculoskeletal applications and beyond, there are a few considerations to take into account. First, HUCMSCs are a heterogeneous population. Following the work that has been done in the bone marrow community with identifying mesenchymal stem cell clones with chondrogenic potential [10] might be valuable for applications such as the IVD. In addition, banking of HUCMSCs [11] is becoming a viable option as companies are entering this market, in which there are two business models: one to collect autologous cells for a child at a cost to the parents, and another to collect cells for allogeneic banking, perhaps to use in a tissue-typing application. Although there is evidence that HUCMSCs might be tolerated in allogeneic transplantation [12], there is the concern that HUCMSCs might experience a loss in their immunosuppressive or immunotolerant character upon differentiation, as has been observed with mesenchymal cells from bone marrow [13]. However, there is recent evidence that HUCMSCs may retain favorable immunocompatibility after differentiation $[14,15]$.

HUCMSCs offer numerous advantages, including multipotency, low cost, availability, commercial relevance and availability of banking, absence of donor site morbidity, political neutrality, high passage potential, and potential immunocompatibility following differentiation [4]. Chon and colleagues provide us another example of the limitless possibilities with HUCMSCs, underscoring the opportunity to guide HUCMSC differentiation even in the absence of serum and growth factors and further supporting the role of HUCMSCs as a promising cell source for IVD regeneration.

\section{Abbreviations}

HUCMSC: Human umbilical cord mesenchymal stromal cell;

IVD: Intervertebral disc; TGF: Transforming growth factor.

\section{Competing interests}

The author declares that he has no competing interests.

Published: 25 Nov 2013

\section{References}

1. Chon BH, Lee EJ, Jing L, Setton LA, Chen J: Human umbilical cord mesenchymal stromal cells exhibit immature nucleus pulposus cell phenotype in a laminin-rich pseudo-3D culture system. Stem Cell Res Ther 2013, 4:120.

2. Mitchell KE, Weiss ML, Mitchell BM, Martin P, Davis D, Morales L, Helwig B, Beerenstrauch M, Abou-Easa K, Hildreth T, Troyer D, Medicetty S: Matrix cells from Wharton's jelly form neurons and glia. Stem Cells 2003, 21:50-60.

3. Bailey MM, Wang L, Bode CJ, Mitchell KE, Detamore MS: A comparison of human umbilical cord matrix stem cells and temporomandibular joint condylar chondrocytes for tissue engineering temporomandibular joint condylar cartilage. Tissue Eng 2007, 13:2003-2010.

4. Wang L, Ott L, Seshareddy K, Weiss ML, Detamore MS: Musculoskeletal tissue engineering with human umbilical cord mesenchymal stromal cells. Regen Med 2011, 6:95-109.

5. Leckie SK, Sowa GA, Bechara BP, Hartman RA, Coelho JP, Witt WT, Dong QD, Bowman BW, Bell KM, Vo NV, Kramer BC, Kang JD: Injection of human umbilical tissue-derived cells into the nucleus pulposus alters the course of intervertebral disc degeneration in vivo. Spine J 2013, 13:263-272.

6. Ruan D, Zhang Y, Wang D, Zhang C, Wu J, Wang C, Shi Z, Xin H, Xu C, Li H, He Q: Differentiation of human Wharton's jelly cells toward nucleus pulposus-like cells after coculture with nucleus pulposus cells in vitro. Tissue Eng Part A 2012, 18:167-175.

7. Nekanti U, Dastidar S, Venugopal P, Totey S, Ta M: Increased proliferation and analysis of differential gene expression in human Wharton's jellyderived mesenchymal stromal cells under hypoxia. Int J Biol Sci 2010, 6:499-512.

8. Wang L, Tran I, Seshareddy K, Weiss ML, Detamore MS: A comparison of human bone marrow-derived mesenchymal stem cells and human umbilical cord-derived mesenchymal stromal cells for cartilage tissue engineering. Tissue Eng Part A 2009, 15:2259-2266.

9. Renth AN, Detamore MS: Leveraging "raw materials" as building blocks and bioactive signals in regenerative medicine. Tissue Eng Part B Rev 2012, 18:341-362.

10. Russell KC, Phinney DG, Lacey MR, Barrilleaux BL, Meyertholen KE, O'Connor $\mathrm{KC}$ : In vitro high-capacity assay to quantify the clonal heterogeneity in trilineage potential of mesenchymal stem cells reveals a complex hierarchy of lineage commitment. Stem Cells 2010, 28:788-798. 
11. Balci D, Can A: The assessment of cryopreservation conditions for human umbilical cord stroma-derived mesenchymal stem cells towards a potential use for stem cell banking. Curr Stem Cell Res Ther 2013, 8:60-72.

12. Weiss ML, Anderson C, Medicetty S, Seshareddy KB, Weiss RJ, VanderWerff I, Troyer D, McIntosh KR: Immune properties of human umbilical cord Wharton's jelly-derived cells. Stem Cells 2008, 26:2865-2874.

13. Chen X, McClurg A, Zhou GQ, McCaigue M, Armstrong MA, Li G: Chondrogenic differentiation alters the immunosuppressive property of bone marrow-derived mesenchymal stem cells, and the effect is partially due to the upregulated expression of B7 molecules. Stem Cells 2007, 25:364-370.

14. La Rocca G, Lo lacono M, Corsello T, Corrao S, Farina F, Anzalone R: Human Wharton's jelly mesenchymal stem cells maintain the expression of key immunomodulatory molecules when subjected to osteogenic, adipogenic and chondrogenic differentiation in vitro: new perspectives for cellular therapy. Curr Stem Cell Res Ther 2013, 8:100-113.

15. Liu S, Yuan M, Hou K, Zhang L, Zheng X, Zhao B, Sui X, Xu W, Lu S, Guo Q: Immune characterization of mesenchymal stem cells in human umbilical cord Wharton's jelly and derived cartilage cells. Cell Immunol 2012, 278:35-44.

$10.1186 /$ scrt353

Cite this article as: Detamore: Human umbilical cord mesenchymal stromal cells in regenerative medicine. Stem Cell Research \& Therapy 2013, 4:142 